Temporal and spatial distribution of global mitigation cost: INDCs and equity

This content has been downloaded from IOPscience. Please scroll down to see the full text. 2016 Environ. Res. Lett. 11114004

(http://iopscience.iop.org/1748-9326/11/11/114004)

View the table of contents for this issue, or go to the journal homepage for more

Download details:

IP Address: 88.128.80.223

This content was downloaded on 03/11/2016 at 15:02

Please note that terms and conditions apply.

You may also be interested in:

Will international emissions trading help achieve the objectives of the Paris Agreement?

Shinichiro Fujimori, Izumi Kubota, Hancheng Dai et al.

The contribution of Paris to limit global warming to $2^{\circ} \mathrm{C}$

Gokul C lyer, James A Edmonds, Allen A Fawcett et al.

Carbon budgets and energy transition pathways

Detlef $P$ van Vuuren, Heleen van Soest, Keywan Riahi et al.

$2{ }^{\circ} \mathrm{C}$ and SDGs: united they stand, divided they fall?

Christoph von Stechow, Jan C Minx, Keywan Riahi et al.

Mitigation choices impact carbon budget size compatible with low temperature goals

Joeri Rogelj, Andy Reisinger, David L McCollum et al.

Zero emission targets as long-term global goals for climate protection

Joeri Rogelj, Michiel Schaeffer, Malte Meinshausen et al.

Impact of the choice of emission metric on greenhouse gas abatement and costs

Maarten van den Berg, Andries F Hof, Jasper van Vliet et al. 


\title{
LETTER
}

CrossMark

OPEN ACCESS

RECEIVED

18 April 2016

REVISED

19 September 2016

ACCEPTED FOR PUBLICATION

11 October 2016

PUBLISHED

26 October 2016

Original content from this work may be used under the terms of the Creative

Commons Attribution 3.0 licence.

Any further distribution o this work must maintain

attribution to the author(s) and the title of the work, journal citation and DOI.

\section{Temporal and spatial distribution of global mitigation cost: INDCs and equity}

\author{
Jing-Yu Liu ${ }^{1,3}$, Shinichiro Fujimori ${ }^{1,2}$ and Toshihiko Masui ${ }^{1}$ \\ 1 Center for Social and Environmental Systems Research, National Institute for Environmental Studies, 16-2 Onogawa, Tsukuba, Ibaraki, \\ 305-8506 Japan \\ 2 International Institute for Applied Systems Analysis, Schlossplatz-1, Laxenburg 2361, Austria \\ 3 Author to whom any correspondence should be addressed. \\ E-mail: liu.jingyu@nies.go.jp \\ Keywords: Paris Agreement, INDC, climate change, equity, mitigation cost, CGE \\ Supplementary material for this article is available online
}

\begin{abstract}
Each country's Intended Nationally Determined Contribution (INDC) pledges an emission target for 2025 or 2030 . Here, we evaluated the INDC inter-generational and inter-regional equity by comparing scenarios with INDC emissions target in 2030 and with an immediate emission reduction associated with a global uniform carbon price using Asian-Pacific Integrated Model/Computable General Equilibrium. Both scenarios eventually achieve $2{ }^{\circ} \mathrm{C}$ target. The results showed that, as compared with an immediate emission reduction scenario, the inter-generational equity status is not favorable for INDC scenario and the future generation suffers more from delayed mitigation. Moreover, this conclusion was robust to the wide range of inequality aversion parameter that determines discount rate. On the other hand, the INDC scenario has better inter-regional equity in the early part of the century than does the immediate emission reduction scenario in which we assume a global carbon price during the period up to 2030. However, inter-regional equity worsens later in the century. The additional emissions reduction to the INDC in 2030 would improve both inter- and inter-regional equity as compared to the current INDC. We also suggest that countries should commit to more emissions reductions in the follow-up INDC communications and that continuous consideration for low-income countries is needed for global climate change cooperation after 2030.
\end{abstract}

\section{Introduction}

In the IPCC's fifth assessment report (AR5) [1], Working Group III noted several scenarios corresponding to the $450 \mathrm{ppm} \mathrm{CO}_{2}$ equivalent concentration stabilization. These scenarios mostly have immediate GHG emissions reductions, and $\mathrm{CO}_{2}$ emissions become zero or negative in the latter half of this century. The Paris Agreement reaffirmed that the ultimate climate goal is the $2{ }^{\circ} \mathrm{C}$ target, which corresponds to about $450 \mathrm{ppm}$ $\mathrm{CO}_{2}$ equivalent concentration stabilization in 2100 [2]. In addition, each country is to submit an Intended Nationally Determined Contribution (INDC) pledge of emission targets for 2025 or 2030 . The summation of all countries' submitted emission targets in 2030 is expected to be larger than the least-cost $2{ }^{\circ} \mathrm{C}$ scenarios shown in AR5, leading to a projected level of 55
$\mathrm{GtCO}_{2}$ eq in 2030. To achieve the $2{ }^{\circ} \mathrm{C}$ target, an additional emission reduction of approximately 15 $\mathrm{GtCO}_{2}$ eq will be required to fill the gap between the post-INDC trajectory and the least-cost $2{ }^{\circ} \mathrm{C}$ scenarios after 2030 [2].

The spatial and temporal distribution of mitigation costs would be different in a mitigation scenario consistent with the INDCs and achieving the $2{ }^{\circ} \mathrm{C}$ target and in the least-cost $2{ }^{\circ} \mathrm{C}$ scenarios. This difference implies that the INDCs influence equity both intergenerationally and inter-regionally.

The discount rate used in projections has a notable influence on the conclusions and policy implications of generational equity issues. Social cost of carbon varies with discount rate and people have conflicting opinions about the urgency for the need for climate policy depending on the discount rate [3]. There have been 
discussions about how to determine the discount rates. The IPCC's second assessment report [4] summarized two major approaches of discounting future values, namely the prescriptive and descriptive approaches. The former begins with ethical considerations, whereas the latter begins with evidence from decisions that people and governments actually make. AR5 [1] looked deeper into the prescriptive approach and reviewed the use of the Ramsey rule of discounting. AR5 concluded that a relative consensus has emerged in favor of setting the pure rate of time preference at 0 and the inequality aversion parameters somewhere from 1 to 3 . The role of the pure rate of time preference and inequality aversion in the discount rate calculation will be explained in section 2.3.1.

Several studies have examined numerical INDC assessment. For example, Iyer et al [5] compared INDC scenarios with an alternative emissions path in which nations cannot undertake mitigation within the INDC period. They found that the use of INDCs made important contributions towards achieving the $2{ }^{\circ} \mathrm{C}$ target. Meinshausen et al [6] assumed one major emitting economy would take the lead in the international emission allocation scheme as an INDC approach and the results showed that there would be a large gap between what emission target was required for this leading country and its current INDC pledge. Fawcett et al [7] studied Paris pledges from a probabilistic perspective and found that INDCs contribute both to reducing the risks of severe outcomes of global warming and to increasing the probability of limiting warming to $2{ }^{\circ} \mathrm{C}$. However, no studies have yet focused on a quantitative generational equity assessment of the INDC and post-INDC time intervals. AR5 also summarizes the effects on the mitigation cost due to delayed mitigation action (WG3 SPM, table 2). Obviously, emissions reductions in a former period contribute to a reduction of the mitigation costs in a later period. Kober et al [8] and Tavoni et al [9] cover, to some extent, the issue of different mitigation costs across regions under LIMITS projects [10]. Although these studies provide meaningful scientific knowledge with regard to mitigation cost distribution and policy suggestions, their scenario frameworks are stylized for an analysis of 2020 climate action and not for 2030 or for the INDCs.

To address this gap, we attempted to answer three research questions. (1) Does the use of INDCs lead to more mitigation costs for future generations as compared with the least-cost $2{ }^{\circ} \mathrm{C}$ scenarios presented in AR5? (2) How do the INDCs affect inter-regional equity? (3) Does greater reduction of emissions in INDCs help to improve generational equity? Here, we have chosen to focus on the $2{ }^{\circ} \mathrm{C}$ goal as a climate mitigation target. However, older generations might change this climate goal if they realize that the cost of mitigation is larger than the benefit. For this reason, we have framed the paper's focus as clearly policy relevant (Paris Agreement).

Section 2 presents the model we used and the scenario framework. The analytical method applied to analyze the results derived from the model is also introduced. Section 3 presents the model results for some of the main indicators and the results for the inter-generational and inter-regional equity analysis. In section 4, we discuss the interpretations and implications of the results, limitations of the study, and future work in this area.

\section{Methodology}

\subsection{Asia-Pacific Integrated Model/Computable General Equilibrium (AIM/CGE)}

We used AIM/CGE, which has been widely used in climate mitigation and impact assessment [11-15]. $\mathrm{AIM} / \mathrm{CGE}$ is a recursive dynamic general equilibrium model that includes 17 regions and 42 industrial classifications. Energy sectors, including power sectors, are disaggregated in detail. Moreover, to assess bioenergy and land use competition appropriately, agricultural sectors are also highly disaggregated [16]. This CGE model was developed based on the 'Standard CGE model' [17], and details of the model structure and mathematical formulas are described in the AIM/CGE basic manual [18].

The production sectors are assumed to maximize profits under multi-nested constant elasticity substitution (CES) functions and each input price. Energy transformation sectors input energy and value added as fixed coefficients of output. They are treated in this manner to appropriately deal with energy conversion efficiency in the energy transformation sectors. Power generation values from several energy sources are combined with a Logit function. This method is adopted in consideration of energy balance because the CES function does not guarantee a material balance. Household expenditures on each commodity are described by a linear expenditure system function. The saving ratio is endogenously determined to balance saving and investment, and capital formation for each good is determined by a fixed coefficient. The Armington assumption is used for trade, and the current account is assumed to be balanced.

In addition to energy-related $\mathrm{CO}_{2}$ emissions, $\mathrm{CO}_{2}$ from other sources, $\mathrm{CH}_{4}$, and $\mathrm{N}_{2} \mathrm{O}$ are treated as $\mathrm{GHG}$ emissions in this model. Non-energy related $\mathrm{CO}_{2}$ emissions consist of land use change and industrial processes. $\mathrm{CH}_{4}$ has various sources, but the main sources are the rice production, livestock, fossil fuel mining, and waste management sectors. $\mathrm{N}_{2} \mathrm{O}$ is emitted by fertilizer applications and livestock manure management, as well as by the chemical industry. Energy-related emissions are associated with fossil fuel consumption and combustion. Non-energy-related emissions, other than land use change emissions, are 
Table 1. Scenario descriptions.

\begin{tabular}{|c|c|c|c|}
\hline & Emissions constraints & & \\
\hline & Before 2030 & After 2030 & $2100\left(\mathrm{~W} \mathrm{~m}^{-2}\right)$ \\
\hline Baseline & No emission constraints & & 7.28 \\
\hline $450 \mathrm{CO} 2 \mathrm{e}$ & Global emission constraint & & 2.86 \\
\hline INDC_450CO2e & Each country's emission constraint & $\begin{array}{c}\text { Global emission } \\
\text { constraint }\end{array}$ & 2.83 \\
\hline SINDC_450CO2e & $\begin{array}{l}\text { Each country's emission constraint }+ \text { additional } \\
\text { emission reduction }\end{array}$ & $\begin{array}{c}\text { Global emission } \\
\text { constraint }\end{array}$ & 2.79 \\
\hline
\end{tabular}

assumed to be in proportion to the level of activities (i.e., output). Land use change emissions are derived from the difference of forest land area from that of the previous year multiplied by the carbon stock density.

The implementation of mitigation is represented by either a global emissions constraint or countrylevel emission constraints. A carbon tax is employed to meet the global or country-level emission constraints, and it is therefore either globally uniform or variable across regions, depending on the type of constraint. The carbon tax makes the price of fossil fuel goods higher when emissions are constrained and promotes energy savings and the substitution of fossil fuels by lower emission energies and also acts as an incentive to reduce the non-energy-related emissions. Gases other than $\mathrm{CO}_{2}$ are weighted by global warming potential and summed as GHG emissions in $\mathrm{CO}_{2}$ equivalents. The revenue from the carbon tax is assumed to be received by households.

\subsection{Scenarios}

Table 1 outlines the four scenarios simulated in this study: Baseline, 450CO2e, INDC_450CO2e, and SINDC_450CO2e. The baseline scenario entails no emissions constraints and follows current trends in energy technologies. The 450CO2e scenario includes emissions constraints that approximately meet the emission radiative forcing target of $2.6-2.8 \mathrm{~W} \mathrm{~m}^{-2}$ in 2100 , which can be interpreted as being in the range of the $2{ }^{\circ} \mathrm{C}$ target. The scenario employs a uniform global carbon price subject to particular emission targets discussed later. The INDC_450CO2e scenario also meets a similar radiative forcing target. INDC pledges are satisfied before 2030. The resulting gap between INDC_450CO2e and 450CO2e in cumulative $\mathrm{CO}_{2}$ emissions prior to 2030 is addressed by further reducing emissions from the $450 \mathrm{CO} 2 \mathrm{e}$ emission trajectory after 2030 in INDC_450CO2e. The SINDC_450CO2e scenario is similar to the INDC_450CO2e scenario, but the INDC target for each country is $20 \%$ higher as compared with the target in INDC_450CO2e. The emissions pathway after 2030 is determined in the same manner as in the INDC_450CO2e scenario. The mathematical method of determining the emissions pathways can be found in the supplementary material (SM). The details of how to construct an emissions constraint in 2030 are also shown in SM; other socioeconomic policies, such as renewable energy targets, are not treated in this study. However, the energy system responds to the carbon price associated with the chosen emissions constraints.

The simulation period is $2005-2100$. The socioeconomic assumptions behind all of the scenarios follow shared socioeconomic pathways (SSP2) [19] socioeconomic assumptions. Socioeconomic assumptions generally include assumptions not only on demographics and economic scale but also on other aspects, such as changes in energy technologies and dietary preference changes. The results might be sensitive to the SSP socio-economic assumptions. Here SSP2 is used as it is seen to be the continuing of the current social, economic and technological trend, leaving the world face moderate challenges to mitigation and adaptation [19]. Population and gross domestic product (GDP) growth are assumed to be the same as in Samir and Lutz [20] and Dellink et al [21] and are presented in the SM. Other energy, land use, and agricultural assumptions are based on Fujimori et al [22]. Countries are grouped into three regions: developing countries, industrial countries, and transition countries. The regional definitions are presented in the SM.

\subsection{Analytical methods}

After we obtained the scenario results, we analyzed the mitigation costs with respect to generational equity. Here, consumption loss or its rate is treated as a representative metric of mitigation costs. To make current and future mitigation costs comparable for inter-generation comparisons and to be able to aggregate the costs across time for both inter-generational and inter-regional analyses, a discount rate is introduced.

We made three types of analysis in section 3. First, we divided the years 2020-2100 into two generations to analyze inter-generational equity. The current generation was defined as 2020-2060 and the future one as 2060-2100. Then, we compared the net present value (NPV) of both generations in terms of absolute consumption loss in the various scenarios. Using the discount rate, we converted future mitigation costs 
into an equivalent present value for 2020 and aggregated the values. The second and third are for interregional equity by evaluating the relationship between the consumption loss rate and GDP per capita across regions in each year as well as their average values for the entire period.

\subsubsection{Ramsey rule and the discount rate}

The discount rates were determined by equation (1) based on the Ramsey rule [23]:

$$
\rho_{\mathrm{t}, \mathrm{r}}=\delta+\eta g_{\mathrm{t}, \mathrm{r}}
$$

Here $\rho_{\mathrm{t}, \mathrm{r}}$ is the discount rate at time $t$ for region $r$, and $\delta$ is the pure rate of time preference for the present. We assumed that the pure rate of time preference was 0 following the practice of previous studies [24, 25], because there is broad consensus for a zero or nearzero pure rate of time preference for the present [1]. The parameter $g_{\mathrm{t}, \mathrm{r}}$ is the consumption growth rate in region $r$, and $\eta$ can be viewed as a measure of intertemporal inequality aversion [26-29]. AR5 [1] explained $\eta$ with the following thought experiment. Imagine an economic policy the aim of which is to increase consumption by 1 unit for every person in a poor group by reducing consumption for every wealthy person by $x$ units. The maximum value of $x$ that a person would accept to implement the policy is a metric of that person's inequality aversion. Values of 1-3 were often used for inequality aversion, with 2 being the most common value $[1,30]$. This implies that the $x$ from the thought experiment ranges from 2 to 8. Arrow et al [30] suggested that $\eta$ reflects the maximum sacrifice one generation should make to transfer income to another generation.

Figure 1 shows how the discount rate varies over time with different values of inequality aversion in Baseline. The discount rates are almost the same across scenarios since the GDP loss is small enough to change discount rates significantly. More detailed consumption growth rates and discount rates in different regions and scenarios are presented in the SM. All of the curves show a declining trend after 2020.

\subsubsection{Equity principles}

Three equity principles are operationalized in our study. First, the use of a discount rate involves equity. The discount rate is determined on the basis of people's inequality aversion, as noted above. Different inequality aversion values are used in the analysis, and their effects on the results are discussed. Second, intergenerational equity was measured by the mitigation cost for current and future generations. In our calculations, we assumed that equity was improved once the relative difference of the NPVs of both generations' consumption losses decreased. Finally, inter-regional equity was measured by mitigation cost differences and, here, consumption loss rate is used as an indicator of mitigation cost.

\section{Results}

\subsection{Main indicators ${ }^{4}$ \\ 3.1.1. GHGemissions}

Figure 2 shows the emission paths for the Baseline, 450CO2e and INDC_450CO2e scenarios. To meet the $2{ }^{\circ} \mathrm{C}$ target, the $450 \mathrm{CO} 2 \mathrm{e}$ scenario assumes a gradually declining global emission path. Total global emissions are $48.9 \mathrm{GtCO}_{2}$ eq in 2020 and $8.76 \mathrm{GtCO}_{2}$ eq in 2100 . In the INDC_450CO2e scenario, each country's emissions between 2020 and 2030 are consistent with its INDC pledge. After 2030, the gap in cumulative $\mathrm{CO}_{2}$ emissions from before 2030 as compared with emissions in the 450CO2e scenario will be filled by allocating additional emissions reductions to the latter part of the period. After 2080, total global emissions reach a lower limit and then remain steady.

Emissions in developing countries, transition countries, and globally are greater in the INDC_450CO2e scenario than those in the 450CO2e scenario from 2020 to 2030, whereas they are about the same in industrial countries. Industrial countries' emissions increase slightly after 2030, primarily because the global uniform carbon price after the INDC period is much lower than it is during the INDC period.

\subsubsection{Carbon price}

In the 450CO2e scenario, a uniform global carbon price is assumed throughout the period. In the INDC_450CO2e scenario, we set country-level carbon prices from 2020 to 2030 and a uniform global carbon price from 2030 to 2100 . Carbon price climbed dramatically after 2075 in the INDC_450CO2e scenario (figure 3(a)), primarily because greater emission reductions are required in the latter part of the century and the marginal cost of emission reduction is rising. Developing countries and transition countries have lower carbon prices in the INDC_450CO2e scenario than in the 450CO2e scenario from 2020 to 2030, whereas industrial countries have higher prices (figure 3(b)).

\subsubsection{Mitigation cost}

Figure 4 presents regional and global consumption loss rates as an indicator of mitigation costs. Global mitigation costs in the INDC_450CO2e scenario are less than those in the $450 \mathrm{CO} 2 \mathrm{e}$ scenario before 2060 , but they are higher afterwards. Because the discount rate is not accounted for in these figures, the mitigation cost of the current and the future generations are not comparable.

\footnotetext{
${ }^{4}$ Here GHG emissions, carbon price and mitigation cost are shown. The energy aspects such as primary energy supply and power generation are shown in SM.
} 

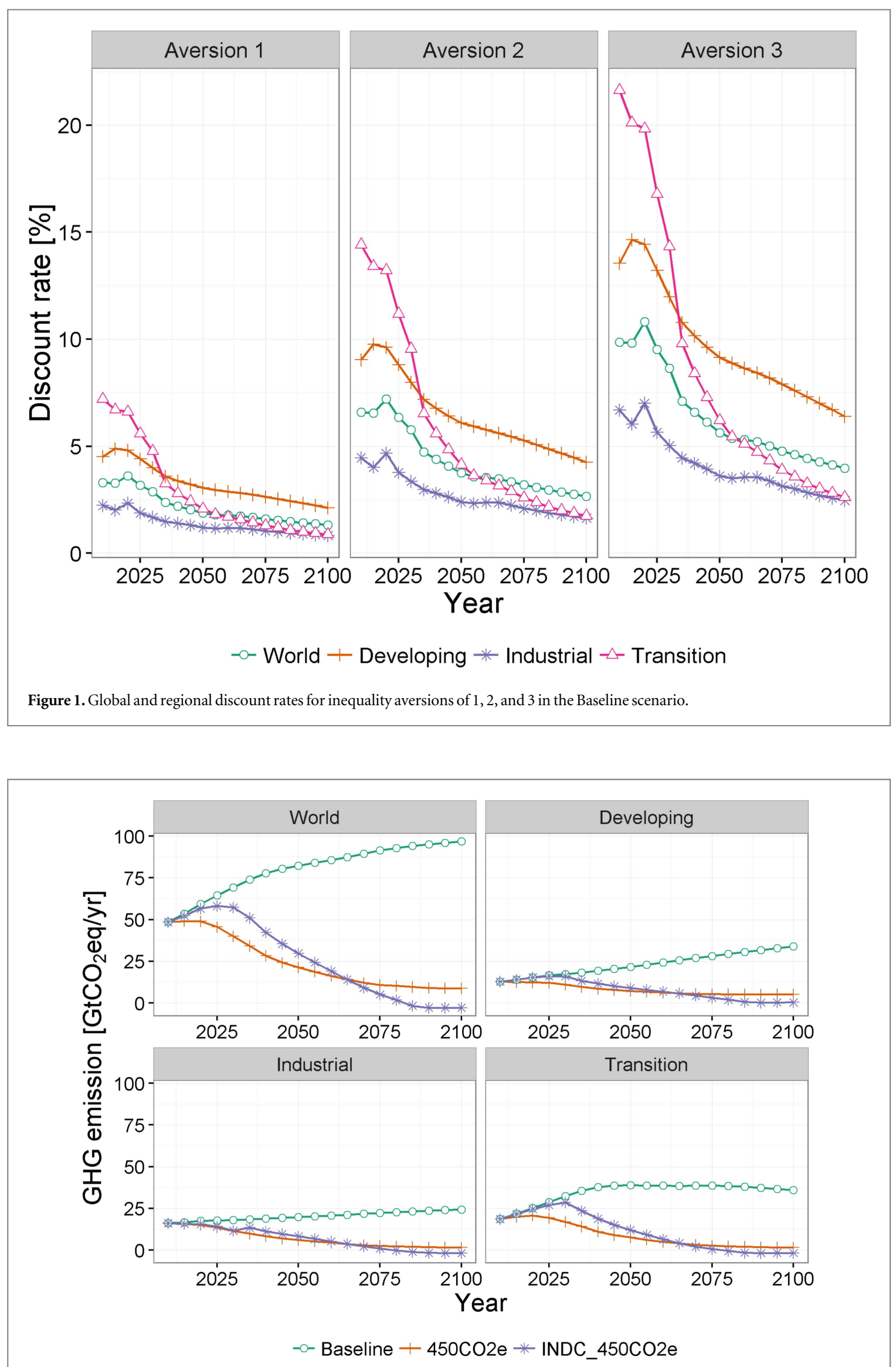

Figure 2. Global and regional GHG emission paths for scenarios Baseline, 450CO2e and INDC_450CO2e. The figure which includes SINDC is shown in SM figure 6. 
a) Global carbon price until 2100

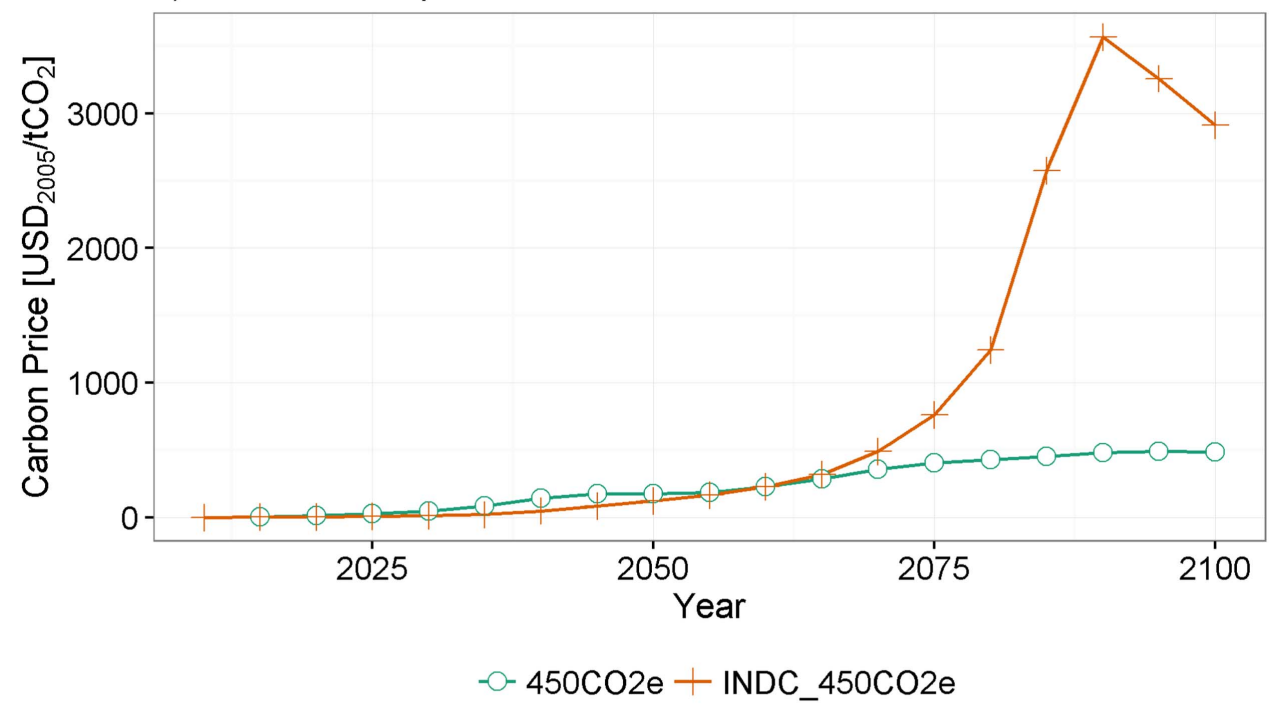

b) Regional carbon price until 2040

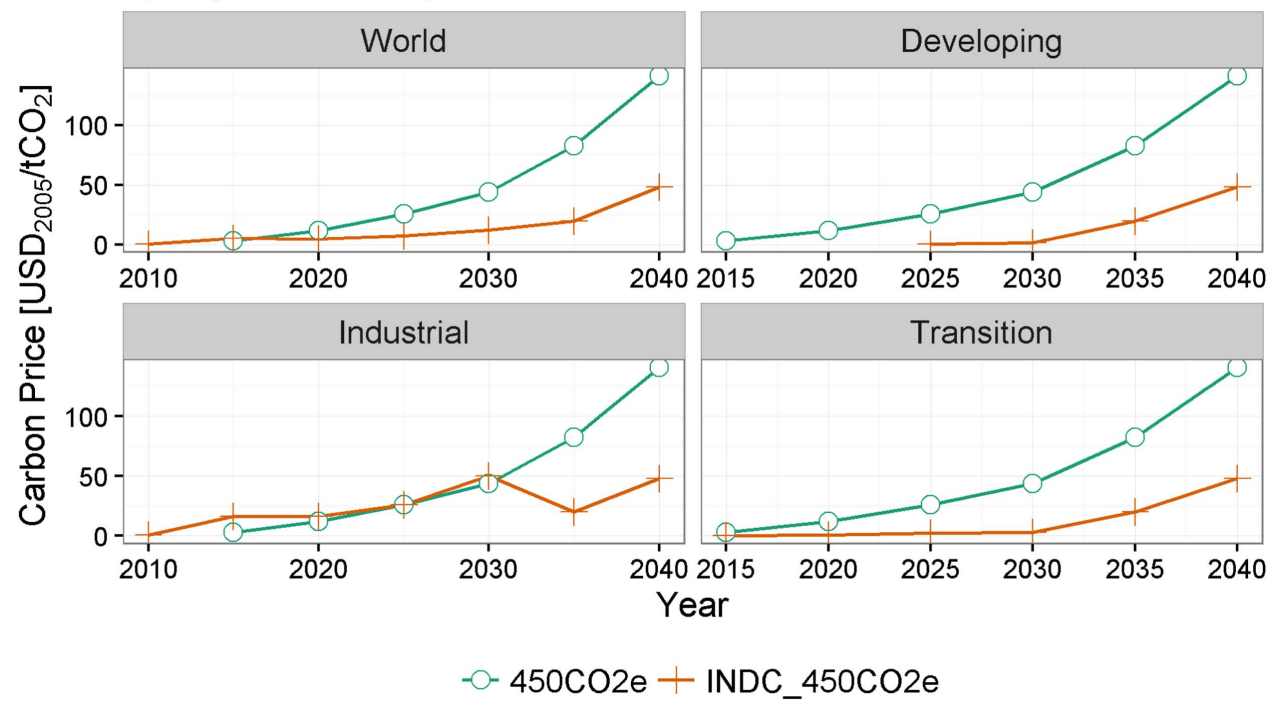

Figure 3. (a) Global carbon price through 2100 and (b) regional carbon price through 2040 for scenarios $450 \mathrm{CO} 2 \mathrm{e}$ and INDC_450CO2e. The figure which includes SINDC is shown in SM figure 7.

\subsection{Inter-generational equity}

We calculated the NPV of consumption losses for the current (2020-2060) and future (2060-2100) generations, as well as the relative differences between the two generations in each scenario. The relative difference was calculated as (NPV of the current generation $-\mathrm{NPV}$ of the future generation)/NPV of the future generation. This difference reflects the relative gap in mitigation costs between the two generations. Hence, it is an indicator of inter-generational equity-smaller values indicate greater inter-generational equity. It is important to note that it is only the absolute value of the relative difference that matters, not whether the value is positive or negative.

Figure 5 shows the consumption losses for the two generations and the relative differences between the two generations' global consumption losses. The discounted consumption loss is lower in the current generation and higher in the future in the INDC_450CO2e scenario as compared with the $450 \mathrm{CO} 2 \mathrm{e}$ scenario for all inequality aversion values. The relative difference decreases as inequality aversion increases in both scenarios, but the relative difference in the 450CO2e scenario is always lower and approaches 0 when the inequality aversion is 3 . Except for the case when the inequality aversion is 3 in the 450CO2e scenario, both scenarios favor the current generation over the future generation. In addition, the INDC_450CO2e scenario always has worse inter-generational equity, regardless of the inequality aversion value. It should be noted that the absolute difference is small when inequality aversion is high, which will not be apparent in the relative differences figure. 


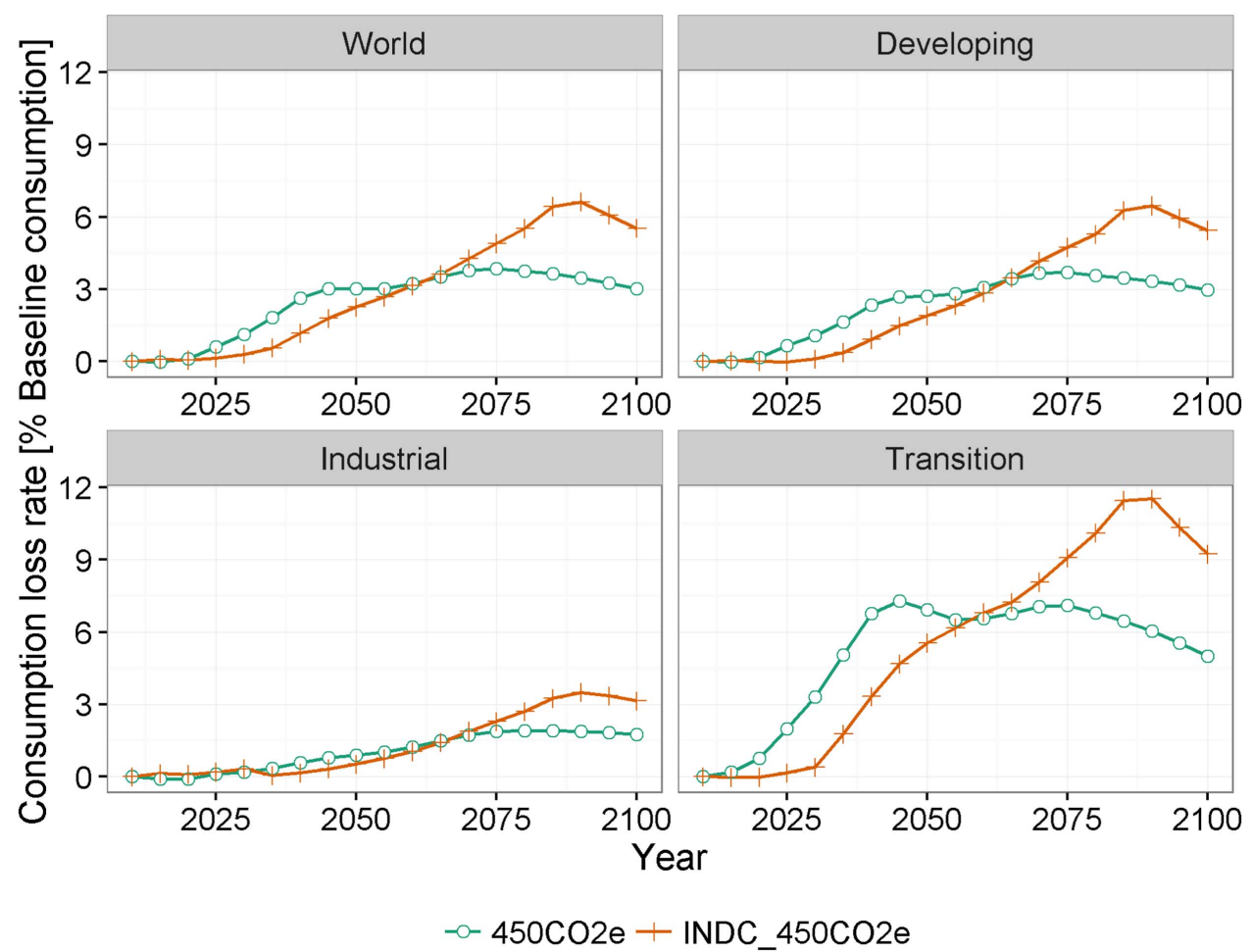

Figure 4. Global and regional mitigation costs for scenarios 450CO2e and INDC_450CO2e. The figure which includes SINDC is shown in SM figure 8.

\subsection{Inter-regional equity}

Figure 6 shows scatter plots for the NPV consumption loss rates of the entire time period of 17 regions versus GDP per capita for the 450CO2e and INDC_450CO2e scenarios. We used the NPV consumption loss rate for each region to represent the average mitigation cost throughout the entire time period. The trend lines of the scatter plots show the trend of the relationship between income and mitigation cost for the different scenarios. A negative sloping trend line indicates that mitigation causes low-income countries to have higher consumption loss rates. The slope of the trend line in scenario INDC_450CO2e is more negative than that of scenario $450 \mathrm{CO} 2 \mathrm{e}$ when the inequality aversion is small (i.e., 1). When the inequality aversion is 2 or 3 , the slope in the INDC_450CO2e scenario is greater than that of the $450 \mathrm{CO} 2 \mathrm{e}$ scenario. This occurs because the impact of the latter part of the century become less important to the NPV of the entire time period when the discount rate is relatively high, and the earlier part of the century is more heavily weighted.

Focusing on the confidence intervals ( $>95 \%$ ) of the slope parameters, the aversion 3 case is relatively small (table 2) and there is no great overlap between $450 \mathrm{CO} 2$ and INDC450CO2e. Therefore, under the assumption of equality aversion parameter 3 , their difference is sufficiently large. However, it would be difficult to distinguish differences between these two scenarios with small aversion parameters 1 .

We also evaluated variations in inter-regional equity over time from the regression parameters of the inter-region scatter plots in different years (figure 7). The discount rate is not used here. In the first part of the period, scenario INDC_450CO2e has better interregional equity compared to scenario $450 \mathrm{CO} 2 \mathrm{e}$. After about 2060, however, the situation is reversed. Focusing on the confidence intervals ( $>95 \%)$ of the slope parameters in figure 7 , in the early and late parts of this century, i.e., before 2045 and after 2075, there is no great overlap between the 450CO2e and INDC450CO2e scenarios. Therefore, the slopes of the curves differ significantly. Between 2045 and 2075, however, the confidence intervals are large and we could not distinguish the slopes of the curves in the two scenarios.

We assumed a uniform carbon price across regions for the entire period in the 450CO2e scenario and from 2030 to 2100 in the INDC_450CO2e scenario. A global carbon price would have a greater adverse impact on low-income countries than on high-income countries. Before 2030, INDC pledges ensure that inter-regional equity improves because low-income regions gain opportunities to develop their economies by pledging lower emission reductions during this period. During this period, a uniform carbon price in $450 \mathrm{CO} 2 \mathrm{e}$ scenario harms the interregional equity. The low-income countries continue to benefit from this economic development from 2030 to 2055 even though the global carbon price increases. Thus, before 2060, inter-regional equity is better in the INDC_450CO2e scenario, but the carbon price after 2060 becomes much higher in the INDC_450CO2e 

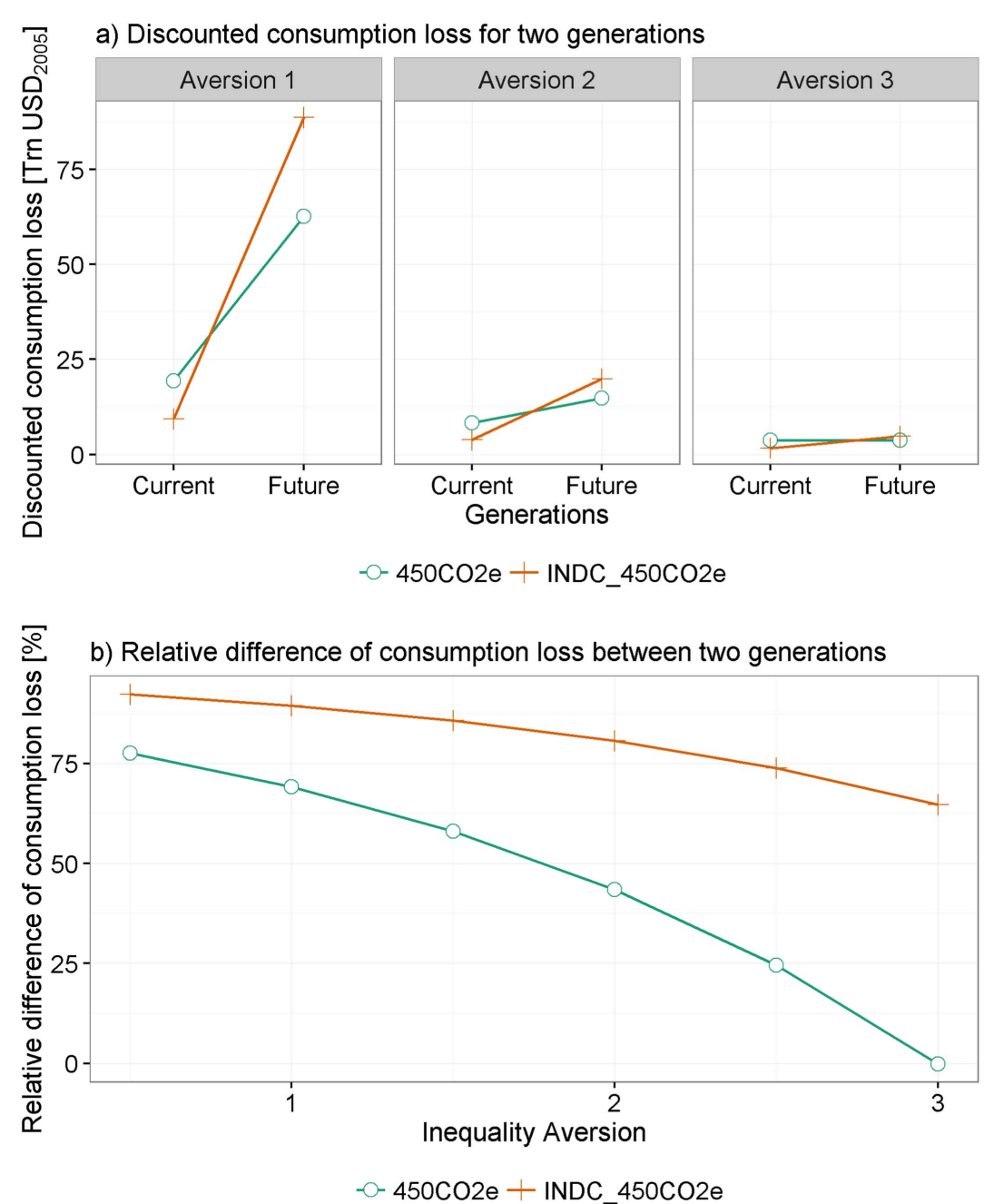

Figure 5. (a) Discounted consumption loss for two generations and (b) relative difference of consumption losses ([NPV current generation-NPV future generation]/NPV future generation) for scenarios 450CO2e and INDC_450CO2e. 1, 2, and 3 represent inequality aversion.

scenario than in the $450 \mathrm{CO} 2 \mathrm{e}$ scenario, and mitigation costs increase for the low-income countries. At this point, the impact of the global carbon price becomes dominant, and the INDC_450CO2e scenario performs worse than the $450 \mathrm{CO} 2 \mathrm{e}$ scenario in terms of inter-regional equity.

\subsection{Stringent INDC scenario analysis}

In the SINDC_450CO2e scenario, we assumed each region had more stringent INDC emission targets to explore how it would affect inter-generational and inter-regional equity. Increasing the emissions reduction target in the INDC period reduced the relative difference of consumption losses between current and future generations compared with the INDC_450CO2e scenario (figure 8).

That the SINDC_450CO2e scenario has a regression line slope that is less negative than the slope of the INDC_450CO2e scenario regression line when the inequality aversion is below 2 (figure 9) indicates greater inter-regional equity. This is primarily because the carbon price is lower in SINDC_450CO2e than it is in INDC_450CO2e, particularly in the latter half of the century.

\section{Discussion and conclusions}

This study assessed inter-generational and interregional equity based on the temporal and spatial distribution of global mitigation costs using AIM/CGE.

\subsection{Interpretations and policy implications}

There are four points to be discussed. First, we observed that inter-generational equity was worse in scenario INDC_450CO2e than it was in $450 \mathrm{CO} 2 \mathrm{e}$, mainly because INDC_450CO2e has a limited amount of emission reductions through 2030 and postpones the reduction efforts into the future as compared with 450CO2e. The inter-generational equity status for the INDC and post-INDC emission pathway is not favorable in this sense, because the future generation suffers from the larger emissions reductions required in the latter part of the century. 


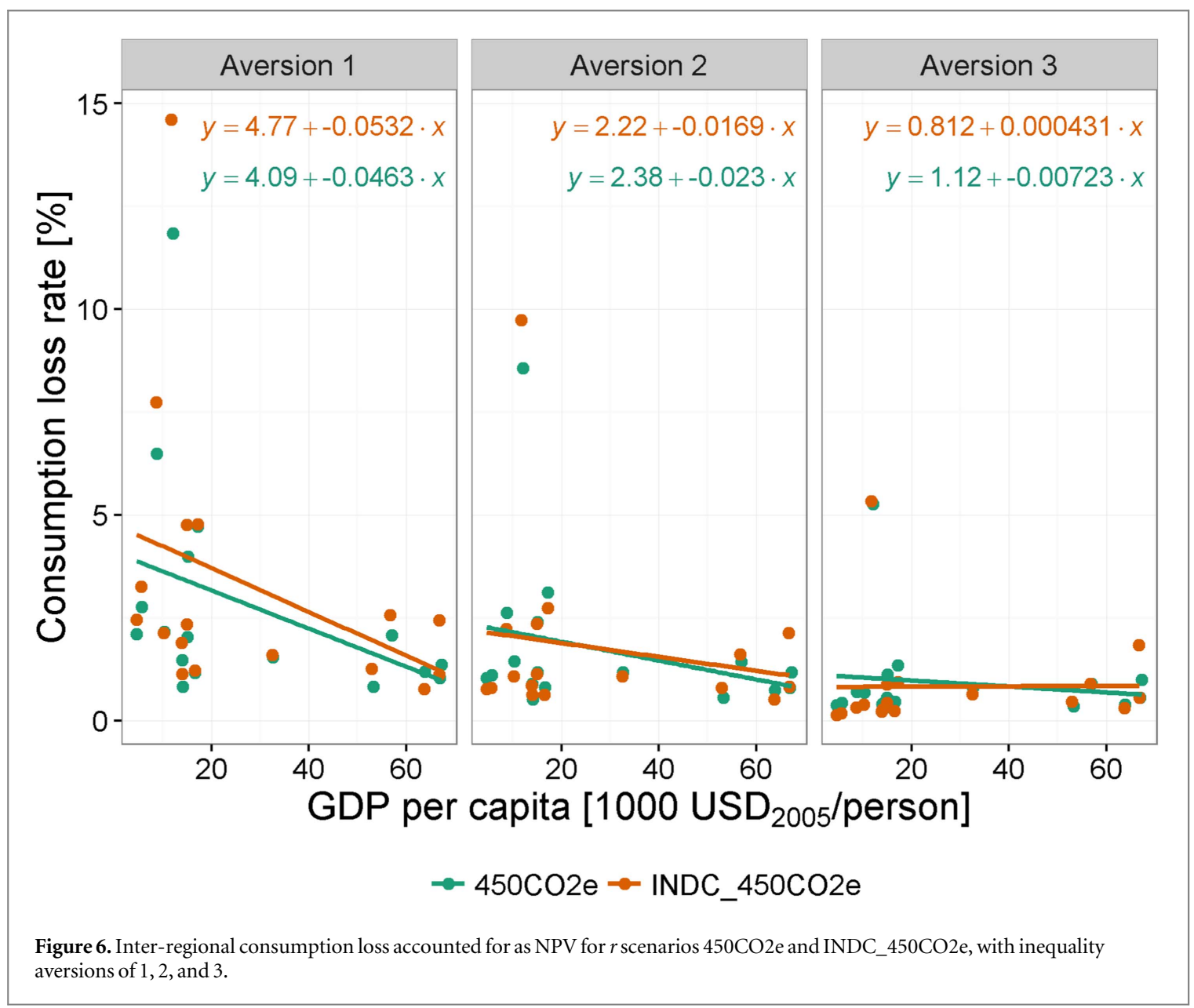

Table 2. Statistical parameters of the estimated slopes for NPV.

\begin{tabular}{|c|c|c|c|c|c|c|c|}
\hline Inequality aversions & Scenarios & $\mu$ & $\sigma$ & $t$ value & $n$ & & $\begin{array}{l}\text { dential } \\
\text { erval }\end{array}$ \\
\hline \multirow[t]{2}{*}{ Aversion 1} & $450 \mathrm{CO} 2 \mathrm{e}$ & -0.0463 & 0.0280 & -1.6390 & 17 & \pm & 0.0115 \\
\hline & INDC450CO2e & -0.0532 & 0.0350 & -1.5172 & 17 & \pm & 0.0133 \\
\hline \multirow[t]{2}{*}{ Aversion 2} & $450 \mathrm{CO} 2 \mathrm{e}$ & -0.0230 & 0.0202 & -1.1390 & 17 & \pm & 0.0057 \\
\hline & INDC450CO2e & -0.0169 & 0.0235 & -0.7158 & 17 & \pm & 0.0042 \\
\hline \multirow[t]{2}{*}{ Aversion 3} & $450 \mathrm{CO} 2 \mathrm{e}$ & -0.0072 & 0.0126 & -0.5720 & 17 & \pm & 0.0018 \\
\hline & INDC450CO2e & 0.0004 & 0.0136 & 0.0316 & 17 & \pm & 0.0001 \\
\hline
\end{tabular}

This conclusion was robust for inequality aversion parameters (i.e., implied discount rates) ranging from 1 to 3 . This would suggest that additional emission reduction efforts in the near term are desirable to achieve the $2{ }^{\circ} \mathrm{C}$ target from the viewpoint of inter-generational equity.

Second, scenario INDC_450CO2e performs better in terms of inter-regional equity during the entire period on average as compared with scenario 450CO2e if the inequality aversion is large. Equity was defined such that high-income regions and low-income regions have close consumption loss rates. Under this principle, INDC_450CO2e has better inter-regional equity in the early part of the century as compared with that of $450 \mathrm{CO} 2 \mathrm{e}$ in which a global carbon price is assumed during the period up to 2030. However, this is not the case for the latter part of the century because of the drastic increase of mitigation costs in this period.

Third, the modified INDC scenario, SINDC_450$\mathrm{CO} 2 \mathrm{e}$, had increased emission reductions prior to 2030. Inter-generational equity improved as compared with INDC_450CO2e, although it still was worse than inter-generational equity with 450CO2e. Furthermore, its average inter-regional equity was also better than that of INDC_450CO2e. The Paris Agreement states that emissions targets will be reviewed and revised in 2020 [2]. This implies that there is still room to enforce stronger emissions reduction for 2030. Our results indicate that each country should adjust its target and commit to greater emissions reductions in the follow-up INDC communications.

Moreover, although we did not consider a specific burden-sharing scheme after 2030 in this study, 


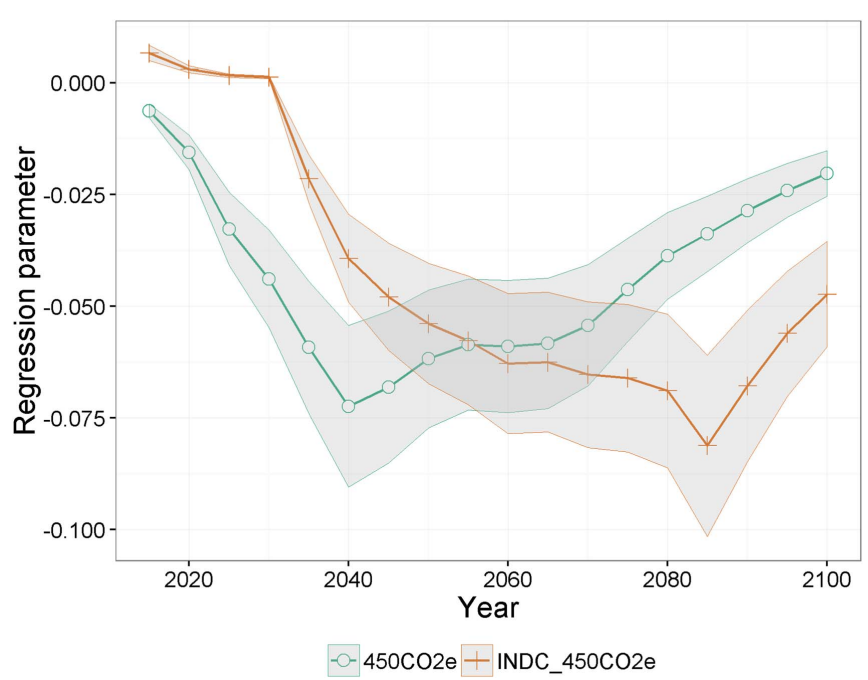

Figure 7. The slope of regressed parameters for each year through 2100 for scenarios 450CO2e and INDC450CO2e. Each undiscounted year's consumption loss rate was regressed for each year.

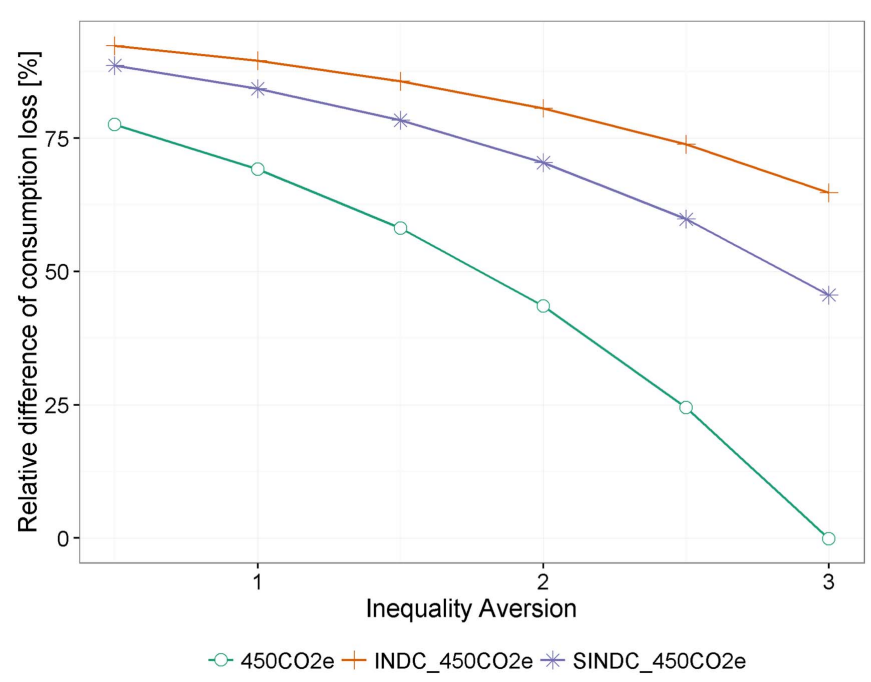

Figure 8. Mitigation cost comparison between current and future generations for inequality aversions of 1,2 , and 3 in scenarios 450CO2e, INDC_450CO2e, and SINDC_450CO2e. The definition of relative difference of consumption loss is the same with that in figure 5(b).

we surmise from the inter-regional equity results that a global uniform carbon price is relatively harmful for developing countries. Considering interregional equity, global carbon pricing should be avoided. However, a global carbon price is the best solution to achieve our climate goals efficiently. Therefore, we may be better off if we find intermediate solutions. Also, it seems that ongoing consideration for low-income countries will be needed as part of global climate change cooperation after 2030 .

\subsection{Limitations and future steps}

There are four points with respect to limitations of this study and future steps. First, the 21st Conference of Parties (COP21) reached an agreement to pursue efforts to limit the global temperature increase to $1.5^{\circ} \mathrm{C}$ above pre-industrial levels. How would the status of generational equity change assuming we follow the INDC pledges and the achievement of the $1.5^{\circ} \mathrm{C}$ target by the year 2100 ? We have not yet addressed this issue but regard it as a next step in our study of equity in climate change policy.

Second, in this study we only considered distribution equity in terms of the distribution of global mitigation costs. Historical responsibilities, compensatory justice, and other factors that may also be relevant to the equity discussion [4] were not considered. For example, many studies working on equity issues discuss cumulative emission allocation schemes [31-35], which are not discussed in this paper. Meanwhile, a focus of recent studies has been the emissions transfer from developed countries to developing countries through international trade [36-40]. This emissions 


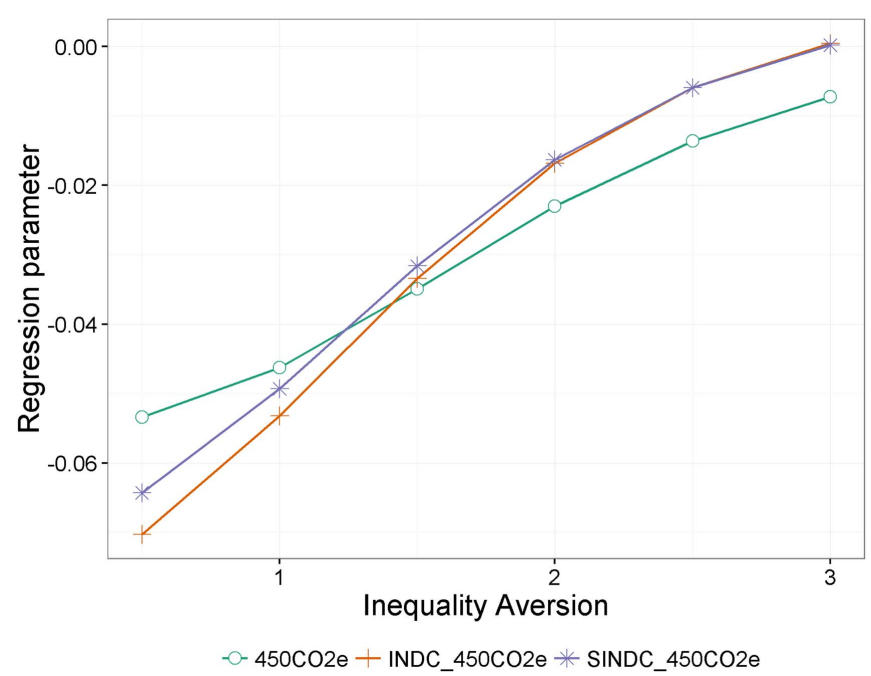

Figure 9. The slope of the regressed parameters for different inequality aversion parameters for scenarios 450CO2e, INDC450CO2e, and SINDC450CO2e. Consumption loss was accounted for as NPV and the different aversion parameters were regressed.

accounting method is certainly relevant to the equity debate, but it was not considered in this study.

Third, here we only considered mitigation costs, negative impacts of climate change and adaptation costs are obviously important elements of the generational equity issue. Although mitigation cost assessment is a prioritized area in terms of INDCs and emission reduction targets, impact and adaptation aspects need to be considered in future studies.

Finally, we assumed that each year's emissions after 2030 were adjusted to fill the gap between the immediate emission reduction scenario and the INDC emission targets during the INDC period. In future studies, we may try to use an emission INDC pathway derived from some type of intertemporal model, for example, the DICE model.

\section{Acknowledgments}

This study is supported by The Environment Research and Technology Development Fund 2-1402 and S14-5 of the Ministry of the Environment, Japan, and JSPS KAKENHI (Grant Number JP16K18177). The authors are most grateful to the generosity of these funds.

\section{References}

[1] IPCC 2015 Climate Change 2014: Mitigation of Climate Change vol 3 (Cambridge: Cambridge University Press)

[2] UNFCCC 2015 Adoption of the Paris Agreement FCCC/CP/ 2015/L.9/Rev.1

[3] Anthoff D, Tol R S and Yohe G 2009 Discounting for climate change Economics 3 1-22

[4] IPCC 1995 Climate Change 1995-Economic and Social Dimensions of Climate Change: Contribution of Working Group III to the Second Assessment Report of the Intergovernmental Panel on Climate Change (New York: Cambridge University Press)

[5] Iyer G C et al 2015 The contribution of Paris to limit global warming to $2{ }^{\circ} \mathrm{C}$ Environ. Res. Lett. 10125002
[6] Meinshausen Met al 2015 National post-2020 greenhouse gas targets and diversity-aware leadership Nat. Clim. Change 5 1098-106

[7] Fawcett A A et al 2015 Can Paris pledges avert severe climate change? Science $3501168-9$

[8] Tavoni M et al 2013 The distribution of the major economies' effort in the durban platform scenarios Clim. Change Econ. 04 1340009

[9] Kober T, van der Zwaan B C C and Rösler H 2014 Emission certificate trade and costs under regional burden-sharing regimes for a $2{ }^{\circ} \mathrm{C}$ climate change control target Clim. Change Econ. 051440001

[10] http://feem-project.net/limits/

[11] Hasegawa T et al 2016 Economic implications of climate change impacts on human health through undernourishment Clim. Change 136 189-202

[12] Mittal Set al 2016 Bridging greenhouse gas emissions and renewable energy deployment target: comparative assessment of China and India Appl. Energy 166301-13

[13] Dai H et al 2016 Key factors affecting long-term penetration of global onshore wind energy integrating top-down and bottomup approaches Renew. Energy 85 19-30

[14] Hasegawa T et al 2015 Consequence of climate mitigation on the risk of hunger Environ. Sci. Technol. 49 7245-53

[15] Fujimori S et al 2014 The effectiveness of energy service demand reduction: a scenario analysis of global climate change mitigation Energy Policy 75 379-91

[16] Fujimori S et al 2014 Land use representation in a global CGE model for long-term simulation: CET versus logit functions Food Secur. 6 685-99

[17] Lofgren H, Harris R L and Robinson S 2002 A Standard Computable General Equilibrium (CGE) Model in GAMS vol 5 (Washington, DC: International Food Policy Research Institute)

[18] Fujimori S, Masui T and Matsuoka Y 2012 AIM/CGE [basic] Manual Center for Social and Environmental Systems Research, NIES, Tsukuba, Japan

[19] O'Neill B C et al 2014 A new scenario framework for climate change research: the concept of shared socioeconomic pathways Clim. Change $122387-400$

[20] Samir K and Lutz W 2014 The human core of the shared socioeconomic pathways: population scenarios by age, sex and level of education for all countries to 2100 Glob. Environ. Change (doi:10.1016/j.gloenvcha.2014.06.004)

[21] Dellink Ret al 2015 Long-term economic growth projections in the shared socioeconomic pathways Glob. Environ. Change (doi:10.1016/j.gloenvcha.2015.06.004) 
[22] Fujimori S, Masui T and Matsuoka Y 2014 Development of a global computable general equilibrium model coupled with detailed energy end-use technology Appl. Energy 128 296-306

[23] Ramsey F P 1928 A mathematical theory of saving Econ. J. 38 543-59

[24] Cline W R 1992 The Economics of Global Warming (Washington, DC: Institute for International Economics)

[25] Arrow K J 1999 Discounting, morality, and gaming Discounting and Intergenerational Equity ed P R Portney and J J Weyant (Washington, DC: Resources for the Future) pp 13-21

[26] Dasgupta P 2008 Discounting climate change J. Risk Uncertain. 37 141-69

[27] Gollier C 2008 Discounting with fat-tailed economic growth J. Risk Uncertain. 37 171-86

[28] Garnaut R 2008 Measuring the immeasurable: the costs and benefits of climate change mitigation Asian-Pac. Econ. Literature 22 1-13

[29] Arrow Ket al 2004 Are we consuming too much? J. Econ. Perspect. 18 147-72

[30] Arrow K J 2013 How should benefits and costs be discounted in an intergenerational context? The views of an expert panel (19 December 2013) Resources for the Future Discussion Paper No. 12-53 (http://ssrn.com/abstract $=2199511$
[31] Matthews H D et al 2014 National contributions to observed global warming Environ. Res. Lett. 9014010

[32] Raupach M R et al 2014 Sharing a quota on cumulative carbon emissions Nat. Clim. Change 4 873-9

[33] Glen P P et al 2015 Measuring a fair and ambitious climate agreement using cumulative emissions Environ. Res. Lett. 10 105004

[34] Zhou P and Wang M 2016 Carbon dioxide emissions allocation: a review Ecol. Econ. 125 47-59

[35] Tavoni M et al 2015 Post-2020 climate agreements in the major economies assessed in the light of global models Nat. Clim. Change 5 119-26

[36] Peters G P and Hertwich E G $2008 \mathrm{CO}_{2}$ embodied in international trade with implications for global climate policy Environ. Sci. Technol. 42 1401-7

[37] Jakob M and Marschinski R 2013 Interpreting trade-related $\mathrm{CO}_{2}$ emission transfers Nat. Clim. Change 3 19-23

[38] Springmann M 2014 Integrating emissions transfers into policy-making Nat. Clim. Change 4 177-81

[39] Kander A et al 2015 National greenhouse-gas accounting for effective climate policy on international trade Nat. Clim. Change 5 431-5

[40] Liu Z et al 2016 Targeted opportunities to address the climatetrade dilemma in China Nat. Clim. Change 6 201-6 